\title{
The Impact of the Application of University Governance: Exploratory Study At The Northern Technical University
}

\author{
Mostafa M. Sedeeq, Bakr Ayoob Saleh, Ahmed R. Mohammed
}

M8747104@gmail.com, ayoob.b.2016@ntu.edu.iq, ahm.rakan@utu.edu.iq

Northern Technical University, Mosul, Iraq

\begin{abstract}
This study aims to investigate the impact of the application of university governance exploratory study. In addition, It studies the concept of corporate governance in general afterward from effective methods in controlling and organizing institutions, as well as the concept of university governance, principles, standards and the most important goals upon which it is based, as establishing the rules of governance in managing university affairs while leaving room for each university to adopt its reputation and image through Its performance and its own standards would elevate the university's educational and administrative systems to better levels. achieving a competitive advantage in the quality of university outcomes, a questionnaire was prepared according to the examination method by choosing one of the answers yes or no and distributing them to the study community represented by the Northern Technical University by selecting a sample of academics, administrators and technicians.
\end{abstract}

Keywords: Governance, University Governance, University Education.

\section{A. Introduction}

University education is the basic building block for building a generation armed with the acquired knowledge, which must be of a high degree of quality, which cannot be achieved without the requirements of university governance in the field of collective involvement of decisions related to educational curricula and scientific research and getting benefit from technical development, which contributes to the preparation of scientific cadres in various disciplines. Then achieving sustainable human development as well as the economic return on investing these energies in many areas, and therefore the research problem relates to the extent of application of mechanisms and requirements for university governance at the Northern Technical University, and show the most important obstacles and problems that prevent the application of university governance. In order to achieve the goals and hypotheses of the research, the research was divided into three sections, the first topic included the research methodology, while the second topic included the theoretical aspect, and the third topic dealt with the exploratory study, and finally the conclusions and recommendations.

\section{The problem of the research:}

Universities are one of the civilizational edifices in attracting students and developing their capabilities and abilities, and then qualifying them scientifically to manage and lead all aspects 
of life. To achieve this goal, it is required to pick up mechanisms and reliable leaders in the applying of current and future policies and plans by involving all elements of the educational in decision-making processes and stages of its implementation in accordance with mechanisms and approaches to keep pace with modern scientific developments without neglecting the requirements of the surrounding external environment, whether at the local, regional or international community level. Related problems in applying university governance in Northern Technical University are:

1- The reality of applying the mechanisms and requirements.

2- The faced obstacles in applying.

\section{The importance of the research:}

University education is the basic building block for building a generation armed with the acquired knowledge, which must be of a high degree of quality, which cannot be achieved without the requirements of university governance in the field of collective involvement of decisions related to educational curricula and scientific research and get benefit from technical development, which contributes to the preparation of scientific cadres With various specializations, then achieving sustainable human development as well as the economic return on investing these energies in many fields

\section{The Objectives of the research:}

The research seeks to define the concept and goals of university governance, whose application leads to change the horizons of the educational process in all its forms and transferring it from the traditional side to the aspects of openness in a world characterized by change and continuous development and then creating a qualitative leap to change the reality of the confined situation in the traditional plans and methods prepared in advance, Outdated, as well as showing the concept, goals and advantages of university education.

\section{The research hypothesis:}

The research is based on the following hypotheses:

1. There is no application of university governance mechanisms and requirements at the Northern Technical University.

2. There are many obstacles to applying the mechanisms and requirements of university governance at the Northern Technical University.

\section{B, Literature Review}

This topic deals with the objectives of governance in general then explaining its concept, goals, principles, and criteria based on. Corporate governance is one of the effective methods in controlling and organizing institutions and companies, and it is defined as "a set of laws, rules, regulations, and decisions that seek to achieve efficiency and effectiveness in performance by adopting a set of effective and appropriate methods to achieve the goals of the company" (Layth and others: 2013: 99).

\section{The second topic the theoretical side}


First: corporate governance: It is the system through which the company's business is directed and monitored at the highest levels in order to achieve its goals and fulfill the requirements for responsibility, integrity and transparency (Abu Hamam: 2009: 15).

Second: the objectives of corporate governance: governance works to achieve many goals, the most important of which are (Umriya: 2014: p. 8):

- The separation between company ownership and management,

- Determine the appropriate structure for the company,

- Follow-up to the review and amendment of laws governing the performance of companies,

- Evaluating the performance of senior management,

- Assist decision makers in building an advanced strategy,

- Attracting investments, whether foreign or domestic and to limit the flight of national capital abroad.

- Increasing the management's ability to motivate employees

Third: university governance: establishing the rules of governance would raise the educational and administrative systems at the university to better levels. In order to achieve comprehensive quality and performance, the university should adopt appropriate and effective strategies to achieve its destination and strategic goals. By this, they mean the systems that govern relations between the main parties that affect performance, and also include the fundamentals of strengthening the university in the long term and determining responsibility and officials (Al-Otaibi: 2018: p. 947).

Fourth: principles of university governance:

four principles can be clarified (Muhammad: 2018: pp. 55-56):

1. Transparency: It means clarity of what is going on and happening within the university with the ease of flowing accurate and objective information and its ease of use and its application by employees,

2. Accountability: It means that officials within the university's administrative structure, each according to its powers, should ask and hold accountable to the subordinate for his actions through appropriate evaluation of these actions,

3. Effective participation: It means the role of academic and administrative bodies, students and society to participate in setting policies, of university life, developing existing educational programs, and creating new programs.

4. The principle of job empowerment: It means the availability of an organizational strategy, which aims to give wide freedom within the university to make decisions and solve problems.

Fifth: The importance of university's governance: 
Governance has become a very important issue in the field of university education, as university education has faced drastic changes during the past decades, represented by the following (Burqaan and Qurashi: 2012: pp. 11 - p. 12):

- The increase in social demand, coupled with an increase in population growth,

- The emergence of new types of university education through public or private universities,

- The emergence of new patterns of education, such as open education or distance education.

- The increasingly international character of university education,

- Research, innovation and benefit from knowledge production,

- The lack of scientific research opportunities, including the lack of cadres and laboratories.

\section{Sixth: the goals of university governance:}

The goals of university governance can be identified as follows (Bashir: 2019: 36).

- Improving and developing the educational performance of the university.

- Assist the university administration in adopting a sound strategy that leads to achieving efficient performance.

- Improve the reputation of universities at the level of the internal and external environment.

- Enhancing the effectiveness of universities.

- Confirm the responsibilities of the administration, evaluate its performance,

- Presenting a clear structure through which the goals of the university and ways to achieve those goals

\section{Seventh: the standards of university governance:}

A set of criteria, based on developing a thorough and accurate evaluation, is needed to the extent in achieving the university goals relative to intended principles. The standards of university governance can be determined with the following (Sanaa: 2017: pp. 26- p. 28):

A. Mission and goals: One of the main elements in evaluating university governance systems is the general structure of the education system and the interaction between universities and the state. One aspect of governance is to secure the resources necessary to implement the goals and mission of the university, as well as to monitor the performance and accountability of managers of institutions at the highest levels.

B. Management orientation: This means the extent to which the university follows the results-based management that is consistent with modern management practices. This standard includes some indicators including (accepting and registering students, identifying rewards and promoting teaching staff and employees, establishing and maintaining facilities; the method for selecting the university president and members of its administrative bodies, And specifying their tasks, responsibilities, and administrative hierarchy, as well as the structures of management, departments and units, their tasks and responsibilities, limits of their accountability and mechanisms for evaluating their performance). 
C. Independence: This standard deals with financial and academic independence, while acknowledging the important practical differences between them.

D. Accountability: As an aspect of governance, this indicates the accountability of the teaching and administrative staff, as well as its link to assessing the achievement of institutional goals.

Eighth: Obstacles to University Governance: obstacles can be categorized as follows (Izzat: 2013: pp. 4 - p. 5):

- The prevailing culture in society and the university: This means the absence of a method of dialogue and discussion as well as the absence of transparency and accountability

- The general political climate: The political climate of the country affects the degree of interest of the university family in its own affairs within the walls of the university, such as the absence of democracy in various fields.

- The way the university is managed: The problem of university administration appears in particular when selecting faculty members and university leaders in general, from the university president to deans of colleges and heads of departments.

- The idea of students' evaluation of the academic performance of the faculty members: The students 'evaluation of the faculty member is considered a standard for measuring performance and continuation in the academic work, and the related promotions, grants, etc.

- The politicization of university education reforms: This is highlighted through the marginalization of members of the university family in the decision-making process as well as the reforms that concern their affairs and affect them in the first place.

Ninth: university education:

1. The concept of university education: University education helps individuals expand their knowledge and skills, as well as express their ideas clearly, both verbally or in writing, understand abstract concepts and theories, and increase their understanding of the world and their society (Al-Naeli: 2017: p. 2).

2. Targets for university education: The World Bank adopted the education strategy until the year 2020 through the slogan "learning for all", as it emphasized the need to invest in human skills and cadres to achieve this goal through a set of indicators that can be summarized as follows (Al-Naimi: 2017: p. 13) :

a. Education is the key to achieving development and growth.

b. Linking university enrollment rates with the educational process improving.

c. Availability of learning for all. 
d. Equality and justice in the field of education between different groups and both sexes, and not be confined to the gifted and distinguished.

e. Lifelong learning according to the principle of "invest early / invest smartly / invest for everyone".

f. Reach advanced levels within international standards.

3. Quality of university education: Quality is one of the most important means and methods for improving the education and raising the level of its performance is defined as "translating the needs and expectations of the beneficiaries of the educational process (students, society, the labor market) into a set of specific characteristics that form the basis for designing educational services and the way to perform work in universities in order to meet the needs and expectations of those groups and achieve their satisfaction with those services that reflect On the extent to which the university's inputs, processes, and outputs meet specific levels that together constitute overall quality standards (Abu Sharia and others: Without a year of publication: p. 5).

4. Conditions for achieving quality in university education: A set of conditions is required as following (College of Sciences: 2016: p. 5):

a. The availability of a mission

b. Necessary resources to implement the mission

c. A system is available to document students.

d. Demonstrate the university's ability to continue to carry out its mission and achieve its goals.

Tenth: The role of university governance in achieving the quality of university education: The basis for progress and civilization is the extent to which nations possess scientific competencies that derive their scientific stock from the quality of education in educational institutions. Accordingly, university governance works to enrich that scientific stock from its outputs through the following (Eid: 2017: p. 509):

- Governance is related to the independence of the university.

- Academic freedom.

- Establishing the rules of governance in managing university affairs

- The economic dimension of university governance

- To share experiences in the aspects of strategies and management.

\section{The third topic of Survey study}

This topic deals with the exploratory study at the Northern Technical University to identify the extent of applying the principles, rules and standards of university governance in them, as a young university which its academic services are countable.

1. A summary of the Northern Technical University: The Northern Technical University was created based on Cabinet Resolution No. 250 of the year 2014 regarding the development of four technical universities, including the Northern Technical University, which was introduced in the year 2014-2015. The University is one of four technical universities in Iraq founded in 2014 after the decision to dissolve the Foundation of Technical education and the formation of 
technical universities instead of. This University includes nine colleges and institutes in engineering, administrative, agricultural, and medical specializations distributed over a vast geographical area that extends in three governorates: Nineveh, Kirkuk, and Salahuddin. The university also includes approximately 25 departments and divisions that are directly related to the president of the university as well as the sub-divisions of the departments and the university directly linked to the Ministry of Higher Education and Scientific.

\section{The objectives of the Northern Technical University:}

- Preparing highly skilled technical staff

- Bridging the gap between traditional scientific and modern scientific approaches.

- Create an applied scientific and research environment

\section{The mission and vision of the university:}

a. Mission: The Northern Technical University is a university that combines modernity in cognitive thinking, tradition and quality in scientific, research and skill giving, and relies on the continuous updating of its technical curricula to keep pace with the changes and scientific developments reflected on the quality of its outputs from graduates to achieve the university's slogan (from the study seats to the work fields).

b. The Vision: The Northern Technical University seeks to be the capital of science and the incubator of scientists in Iraq and the first source for technical graduates with intellectual, emotional, and skill distinction. Bureau for Development Planning in all of Iraq, the first pillar for achieving sustainable development in Iraq, a university of knowledge and applied sciences that elevates the hierarchy of knowledge down to the level of evaluation at the top of the knowledge hierarchy.

4. Data Analysis The results of the survey study: In order to achieve the goals and hypotheses of the research, a questionnaire was prepared and distributed to the research community represented by the Northern Technical University and its sample is represented by a number of academics, administrators and technicians, as 60 forms were retrieved from them (51), i.e. 85\% which is a percentage Very good. The form has been divided into two axes:

The first axis: This axis included (20) questions regarding the reality of the application of university governance, and the results of the responses of the sample members were as in Table No. (1):

Table 1. The reality of the application of university governance.

\begin{tabular}{|c|c|c|c|c|}
\hline percentage & no & percentage & yes & $\begin{array}{c}\text { Question } \\
\text { No. }\end{array}$ \\
\hline $\mathbf{1 6 \%}$ & $\mathbf{8}$ & $\mathbf{8 4 \%}$ & $\mathbf{4 3}$ & 1 \\
\hline $\mathbf{0}$ & $\mathbf{0}$ & $\mathbf{1 0 0}$ & $\mathbf{5 1}$ & 2 \\
\hline $\mathbf{2 7 \%}$ & $\mathbf{1 4}$ & $\mathbf{7 3 \%}$ & $\mathbf{3 7}$ & 3 \\
\hline $\mathbf{3 7}$ & $\mathbf{1 9}$ & $\mathbf{6 3 \%}$ & $\mathbf{3 2}$ & 4 \\
\hline $\mathbf{2 \%}$ & $\mathbf{1 5}$ & $\mathbf{9 8 \%}$ & $\mathbf{5 0}$ & 5 \\
\hline $\mathbf{3 7 \%}$ & $\mathbf{1 9}$ & $\mathbf{7 1 \%}$ & $\mathbf{3 6}$ & 6 \\
\hline
\end{tabular}




\begin{tabular}{|c|c|c|c|c|}
\cline { 4 - 5 } $\mathbf{1 6 \%}$ & $\mathbf{8}$ & $\mathbf{8 4 \%}$ & $\mathbf{4 3}$ & 8 \\
\hline $\mathbf{3 1 \%}$ & $\mathbf{1 6}$ & $\mathbf{6 9 \%}$ & $\mathbf{3 5}$ & 9 \\
\hline $\mathbf{3 9 \%}$ & $\mathbf{2 0}$ & $\mathbf{6 1 \%}$ & $\mathbf{3 1}$ & 10 \\
\hline $\mathbf{4 1 \%}$ & $\mathbf{2 1}$ & $\mathbf{5 9 \%}$ & $\mathbf{3 0}$ & 11 \\
\hline $\mathbf{2 5 \%}$ & $\mathbf{1 3}$ & $\mathbf{7 5 \%}$ & $\mathbf{3 8}$ & 12 \\
\hline $\mathbf{8 \%}$ & $\mathbf{4}$ & $\mathbf{9 2 \%}$ & $\mathbf{4 7}$ & 13 \\
\hline $\mathbf{8 \%}$ & $\mathbf{4}$ & $\mathbf{9 2 \%}$ & $\mathbf{4 7}$ & 14 \\
\hline $\mathbf{2 0 \%}$ & $\mathbf{1 0}$ & $\mathbf{8 1 \%}$ & $\mathbf{4 1}$ & 15 \\
\hline $\mathbf{5 9 \%}$ & $\mathbf{3 0}$ & $\mathbf{4 1 \%}$ & $\mathbf{2 1}$ & 16 \\
\hline $\mathbf{4 3 \%}$ & $\mathbf{2 2}$ & $\mathbf{5 7 \%}$ & $\mathbf{2 9}$ & 17 \\
\hline $\mathbf{4 3 \%}$ & $\mathbf{2 2}$ & $\mathbf{5 7 \%}$ & $\mathbf{2 9}$ & 18 \\
\hline $\mathbf{1 2 \%}$ & $\mathbf{6}$ & $\mathbf{8 8 \%}$ & $\mathbf{4 5}$ & 19 \\
\hline $\mathbf{1 2 \%}$ & $\mathbf{6}$ & $\mathbf{8 8 \%}$ & $\mathbf{4 5}$ & 20 \\
\hline
\end{tabular}

We note from Table No. (1) the following:

1. The majority of the individuals in the research sample agree that the university is announcing its strategy and policies related to the academic and administrative aspects, at a rate of (\%84).

2. The majority of the research sample agreed that the university has a mission, goals and vision that are clear-cut and applicable, at a rate of (..\%100

3. The majority of the members of the research sample agree that the university has transparency about everything that goes on in it with the ease of information flow to the relevant parties, at a rate of $(. \% 73$

4. The majority of the research sample agreed that the university has a system based on questioning and accountability of subordinates, each according to its job location and at a rate of $(.(\% 63$

5. The majority of the individuals in the research sample agree that the university is evaluating the job and administrative performance of educational and administrative cadres. At a rate of $(\% 98$

6. The majority of the research sample agreed that the university gives teaching and administrative cadres and students wide freedom within the university to take decisions and solve problems. And at a rate of $(. \% 71$

7. The majority of the individuals in the research sample agree that the university expands the scope of delegation of authorities and powers according to the distribution of administrative and academic work for the various administrative levels, at a rate of (.(\%63

8. The majority of the research sample agreed that the university discloses its policy in granting fellowships and scholarships, at a rate of (..\%84

9. The majority of the individuals in the research sample agree that the university discloses the standards used in academic and administrative positions, at a rate of (..\%69

10. The majority of the individuals in the research sample agree that the university has an integrated system for the circulation and flow of information electronically for all of its formations, at a rate of $(.(\% 61$

11. The majority of the individuals in the research sample agree, at an average rate of (\%59) that the university enjoys independence in making admission and registration decisions for students and distributing them. At a rate of.

12. The majority of the individuals in the research sample agree that the university depends on the resources allocated to it centrally in the conduct of its work and the assigned tasks, at a rate of $(.(\% 75$ 
13. The majority of the individuals in the research sample agree that the university has special resources for investments and financial fees, at a rate of (. $(\% 92$

14. Also it is agreed that the university allocates part of the private resources as incentives and bonuses, in addition to using them to modernize laboratories and classrooms, at a rate of (. $(\% 92$

15. The majority of the members of the research sample agree that the university has an internet network that enables teaching and administrative cadres to perform their tasks and work easily, at a rate of (. $\% 81$

16. The majority of the members of the research sample agree that the university involves its cadres, students, and representatives of civil society in taking decisions and drawing up established policies at a rate of (. $(\% 41$

17. Most agree that the university involves faculty and students in developing educational curricula at a rate of $(.(\% 57$

18. Most of the answers indicated on university independence in taking decisions to accept or reject students on the basis of their absorptive capacity. At a rate of (. $(\% 57$

19. The majority of the individuals in the research sample agree that the university has specific scientific criteria for accepting students within its formations, at a rate of $(.(\% 88$

20. The majority of the research sample agreed that the university has clear criteria for evaluating faculty and administrative staff. At a rate of $(.(\% 88$

Accepting the first nihilistic hypothesis: According to Table No. (1) it is clear that there is a limited application of university governance in the Northern Technical University in some aspects.

The second axis: This axis included (10) questions regarding the obstacles that prevent the application of university governance and the results of the responses of the sample members were as follows:

Table 2 Obstacles to the application of university governance.

\begin{tabular}{|c|c|c|c|c|}
\hline percentage & No & percentage & yes & Question No. \\
\hline $\mathbf{3 1 \%}$ & $\mathbf{1 6}$ & $\mathbf{6 9 \%}$ & $\mathbf{3 5}$ & 1 \\
\hline $\mathbf{2 7 \%}$ & $\mathbf{1 4}$ & $\mathbf{7 3 \%}$ & $\mathbf{3 7}$ & 2 \\
\hline $\mathbf{4 5 \%}$ & $\mathbf{2 3}$ & $\mathbf{5 5 \%}$ & $\mathbf{2 8}$ & 3 \\
\hline $\mathbf{2 4 \%}$ & $\mathbf{1 2}$ & $\mathbf{7 5 \%}$ & $\mathbf{3 8}$ & 4 \\
\hline $\mathbf{1 0 \%}$ & $\mathbf{5}$ & $\mathbf{9 0 \%}$ & $\mathbf{4 6}$ & 5 \\
\hline $\mathbf{1 4 \%}$ & $\mathbf{7}$ & $\mathbf{8 6 \%}$ & $\mathbf{4 4}$ & 6 \\
\hline $\mathbf{2 5 \%}$ & $\mathbf{1 3}$ & $\mathbf{7 5 \%}$ & $\mathbf{3 8}$ & 7 \\
\hline $\mathbf{1 0 \%}$ & $\mathbf{5}$ & $\mathbf{9 0 \%}$ & $\mathbf{4 6}$ & 8 \\
\hline $\mathbf{1 7 \%}$ & $\mathbf{9}$ & $\mathbf{8 3 \%}$ & $\mathbf{4 2}$ & 9 \\
\hline $\mathbf{2 2 \%}$ & $\mathbf{1 1}$ & $\mathbf{7 8 \%}$ & $\mathbf{4 0}$ & 10 \\
\hline
\end{tabular}

We note from Table No. (2) the following points:

1. The majority of the research sample participants agreed that there is a significant weakness in the culture of dialogue, on one hand among the university itself and between the teaching staff and students on the other hand, at a rate of $(69 \%)$. 
2. The majority of the members of the research sample agree not to give the opportunity to students and teaching staff to express opinions regarding the status of educational curricula and the way they are presented, at a rate of $(73 \%)$.

3. The majority of the research sample agreed that the teaching staff or students do not have the right to object or express an opinion regarding decisions and policies issued by the university presidency, at a rate of $(55 \%)$.

4. The majority of the individuals in the research sample agree that the random acceptance of students in large numbers affects the absorptive capacity on the one hand, as well as scientific sobriety on the other hand, at a rate of $(75 \%)$.

5. The majority of the individuals in the research sample agree that choosing and appointing university presidents and executive positions is central rather than electing them to a feeling of frustration and the inability to change at a rate of $(90 \%)$.

6. The majority of the individuals in the research sample agree that the university's dependence on financial resources allocated to it centrally limits its ability to allocate funds in the areas that it actually needs, at a rate of $(86 \%)$.

7. The majority of the individuals in the research sample agree that the university cannot use all investment income and university fees to enhance and develop its infrastructure, at a rate of $(75 \%)$.

8. The majority of the research sample agreed that the university's commitment to the central laws and regulations limits its ability to make decisions at the academic, administrative, and financial levels by a rate of $(90 \%)$.

9. The majority of the members of the research sample agree that the lack of opportunities for scientific research and its applications due to the lack of financial resources leads to the aversion of those looking for innovation and creativity, at a rate of $(83 \%)$.

10. The majority of the research sample agreed on not accepting the idea of evaluating the performance of the teachers by the students, knowing that they are the most beneficiaries of them in giving the appropriate evaluation to the teachers, at a rate of (78\%).

Accepting the second hypothesis: there are many obstacles related to the dependence on central laws and instructions and thus the apparent impact on its independence in terms of decisions or educational curricula and even financial ones.

\section{Conclusions and recommendations}

1. The theoretical side's conclusions: It can be summarized as follows:

a. University governance works to adapt to the internal and external environmental variables.

b. University governance is a set of laws, regulations and instructions that aim to achieve comprehensive quality and performance excellence by choosing appropriate and effective strategies to achieve the university's goals and strategic goals.

c. Among the most important principles of university governance are transparency, accountability, participation and job empowerment.

d. Mission and goals are among the most important criteria for university governance.

e. Despite the effectiveness of university governance, there are many obstacles facing its application, including the prevailing culture in society, the general political climate, the way the university is run, and the politicization of university education reforms. 
f. University education has become one of the most important sectors facing global competition, with the opportunities and challenges that this represents and a wide field for material and human investment in the era of globalization and the technical revolution that exceeded all limits and horizons.

g. University education is a human right, and therefore equality and justice must be established in the field of education between different groups and both sexes.

h. The quality of university education is achieved through improving the quality of education and improving its performance.

\section{Recommendations}

a. The need for the university to provide the appropriate climate and sufficient space to establish the rules and foundations of a culture of dialogue between it and the teaching, administrative cadres and the representatives of students.

b. The necessity of setting up workshops by engaging teaching staff and student representatives on updating and developing current educational curricula that have become outdated in many departments and in line with technical and scientific development in various fields and to make the educational process outputs in a manner consistent with the requirements of the labor market.

c. In order to reach the scientific sobriety of the university's outputs and to enter into the international classifications, among different universities, it is necessary to establish standards and the scientific basis for accepting students in various disciplines; otherwise, the random acceptance of unplanned numbers of students will greatly limit the achievement of these goals.

d. The necessity for the university to have the independence to choose the administrative leaderships from the top of the university pyramid according to specific criteria built on competence in running and freedom to vote on the basis of transparency and fairness of the results of the selection process outcomes.

e. The necessity for the university to have financial independence in terms of freedom to control the aspects of exchange according to the requirements of the higher interest of the university, which requires a kind of financial decentralization in disposing of its revenues and directing it towards the most important aspects, especially the costs of scientific research and its applications.

\section{Future Studies}

Firstly: the researcher recommends studying the impact of the application of university governance on private universities.

Secondly: the researcher recommends to study the impact of the application of general hospitals

\section{References}

1. Al-Layeth, Ali Abdul-Ghani and others, 2013, the effect of applying rules of governance corporate on the quality of financial reports, Al-Tannany Magazine, Volume 26, Fourth Issue, pp. 96 - p. 110. 
2. Abu Hamam, Majed Ismail, 2009, The Impact of Applying Governance Rules on Accounting Disclosure and Quality of Financial Reports, Unpublished Master Thesis, College of Commerce, Islamic University of Gaza.

3. Umariah, Hamash, 2014, The Impact of Governance on the Level of Accounting Information Disclosure, Unpublished Master Thesis, College of Economic Sciences, Commercial Sciences and Management Sciences, University of D. TaharMoulaySaida, Algeria.

4. Al-Otaibi, Abdullah, 2018, the reality of the application of governance in King Saud University from the viewpoint of faculty members, studies, educational sciences, volume 45, No. 4, Annex 2, University of Jordan, Jordan.

5. Al-Mofez, Khawla, 2018, Applying Governance in Saudi Public Universities: A Proposed Perception. Journal of Educational Sciences - Imam Muhammad bin Saud Islamic University, M1, AR15, 199-286.

6. Muhammad, ReembintThabet, 2019, The governance framework in Saudi universities to achieve a competitive advantage in making decisions according to the aspirations of the Vision 2030, Journal of Educational and Psychological Sciences, Volume III - No. 15, pp. 51 - p. 79. Riyadh, Saudi Arabia.

7. Burqaaan, Ahmad Muhammad Ahmad and Al-Qurashi, Abdullah Ali, University Governance, the Roles and Challenges. International Scientific Conference Management Globalization during Knowledge Era. 15-17 December, 2012, Al-Jinan University - Tripoli, Lebanon.

8. Bashir, Mohamed Hassan, 2019, the foundations and theoretical principles of governance and the requirements for their application in public education in Sudan, Journal of Educational and Psychological Sciences, Volume III - No. 6 - pp. 27 - p. 45, Riyadh, Saudi Arabia.

9. Sana, Jafta, 2017, The Role of University Governance in Improving the Quality of University Education from the Point of View of Stakeholders, Unpublished Master Thesis, Faculty of Economic, Commercial and Management Sciences, Setif University 1, Algeria.

10. Ezzat, Ahmad, 2013, the concept of corporate governance, its purpose and ways to implement it, an article published on the Internet, https://www.facebook.com/notes/ahmed-kamal-noamanvisit date is eleven at night $12 / 17$ / 2019 .

11. Al-Naili, Nebras, 2017, university education and modernizing Iraqi society, an article published on the website of the "Information Network", the date of the visit at 12 noon on Wednesday, 25/25/2019 https://m.annabaa.org/arabic / studies / 10977.

12. Al-Nuaimi, Salah Abdel-Qader, 2017, Enhancing Competitive Capabilities for Education Quality Indicators - Challenges and Strategic Options Available for Higher Education in Iraq - The Arab Journal of Management, Supplement to the Second Issue, Volume 37, Arab Organization for Administrative Development, League of Arab States.

13. College of Science - Quality Assurance Division - 2016 - Quality and University Performance in Arab and International Universities in the Light of International Standards, Al-Muthanna University, Iraq, pp. 1 - p. 17.

14. Abu Sharia, Amer Suleiman Ibrahim and Mutawa, Mesbah Mansour Musa and Khaled, Muhammad Youssef, without a year of publication, quality in educational institutions in Islam, research published on the Internet, https://portal.arid.my/Publications/3dcalfd4be28 -44.docx, visit date is $10 \mathrm{pm}$ on December 25, 2019. 
15. Eid, HalaFawzi Muhammad, 2017, Improving Administrative Performance in Saudi Universities, Journal of Studies in University Education, No. 37 bis, pp. 507 - p. 586. Riyadh, Saudi Arabia 